\title{
Estudio histológico, inmuno-histoquímico y de cultivo celular de mamas humana y canina normal y cancerosa
}

\author{
Histological, immuno-histochemical study and culture of human \\ and canine, normal and cancerous, breast cells
}

\author{
Carine Fernandes $\mathrm{B}_{,}{ }^{1} \mathrm{M} . \mathrm{Sc}$, Marcelo José $\mathrm{V}_{1}{ }^{1} \mathrm{Ph} . \mathrm{D}$, Ricardo Junqueira Del C, ${ }^{2 *} \mathrm{Ph} . \mathrm{D}$, \\ Liana Mesquita $\mathrm{V}^{2}$ M.Sc, Mastoby Martinez M, ${ }^{3}$ M.Sc.
}

\begin{abstract}
${ }^{1}$ Universidad Federal de Viçosa (UFV), Departamento de Biología Animal, Viçosa-MG, Brasil. 2Universidad Federal de Viçosa (UFV), Departamento de Medicina Veterinaria, CEP 36570-000, ViçosaMG, Brasil. 'Universidad de Córdoba, Facultad de Medicina Veterinaria y Zootecnia, Departamento de Ciencias Pecuarias, Montería, Colombia. *Correspondencia: ricarlo@ufv.br
\end{abstract}

Recibido: Marzo de 2011; Aceptado: Enero de 2012.

\begin{abstract}
RESUMEN
Objetivo. Comparar las características morfológicas de células normales y cancerosas derivadas de glándulas mamarias de las especies humana y canina. Materiales y métodos. Fueron colectadas 10 muestras de parénquima mamario normal y 14 de parénquima tumoral de la especie canina, así como seis muestras de parénquima mamario normal y tres de parénquima tumoral de la especie humana. Para el cultivo de células fue utilizada la técnica de cultivo de células de mamíferos y para la histoquímica la técnica de la avidina- biotina- peroxidasa, con utilización del anticuerpo monoclonal 32-2B (anti-desmogléina-1). Resultados. A los estudios histológicos y morfológicos las células de la glándula mamaria normal humana demostraron semejanzas con las células de la glándula mamaria normal canina. Se observó adhesión y proliferación de células normales en ambas especies por aproximadamente tres meses de cultivo. Las células normales de las especies humana y canina mostraron baja actividad de proliferación cuando se compararon con las cancerosas de las especies en estudio. Los grupos de células epiteloides que se adhirieron al sustrato de los dos cultivos tuvieron dependencia de las células estromales, porque en la medida que las células fibroblastoides se retiraron, las células epiteloides detuvieron su crecimiento. Conclusiones. Comparando los resultados obtenidos por medio de análisis inmuno-histoquímico de células normales de mujeres y perras fue posible observar cambios en el patrón de coloración en células cancerosas en ambas especies, demostrando que las estructuras relacionadas con la adhesión celular (desmosomas) pueden estar alteradas.
\end{abstract}

Palabras Clave: Cáncer, glándulas mamarias, mujeres, perros (Fuente: CAB). 


\begin{abstract}
Objective. Compare the morphological characteristics of normal and cancer cells derived from mammary glands of human and canine species. Materials and methods. 10 samples were collected of normal breast parenchyma and 14 from tumor parenchyma of the canine species, as well as six samples of normal breast parenchyma and three-tumor parenchyma of the human species. For the cell culture, a mammal cell culture technique was used, and, an avidin-biotin-peroxidase technique was used for the histochemical culture, with the use of monoclonal antibody 32-2B (anti-desmoglein-1). Results. With histological and morphological studies, the cells of the normal human mammary gland showed similarities with cells of normal canine mammary gland. Adhesion and proliferation of normal cells was observed in both species bin approximately three months of culture. Normal cells of human and canine species showed low proliferative activity when compared with cancerous cells of the species under study. Groups of epithelioid cells that adhered to the substrate of the two cultures had dependence on stromal cells, because as the fibroblastoid cells were removed, epithelioid cells stopped their growth. Conclusions. Comparing the results obtained by immuno-histochemical analysis of normal cells of women and bitches, it was possible to observe changes in the pattern of staining in cancer cells in both species, demonstrating that the structures related to cell adhesion (desmosomes) may be altered.
\end{abstract}

Key words: Cancer, dogs, mammary glands, women (Source: CAB).

\title{
INTRODUCCIÓN
}

La mama es una glándula exocrina, apocrina, de origen ectodérmica, especializada en la producción de leche después de la gestación (1). Está compuesta por conductos formados por células epiteliales que poseen a su alrededor una fina capa de tejido conjuntivo denso y un predominio de tejido conjuntivo adiposo que la Ilena (2). Los tejidos epitelialestienen estructuras de adhesión altamente especializadas que contribuyen en la manutención de su integridad (3). Una de esas estructuras es el desmosoma (4). En el cáncer los desmosomas tienen un gran papel relacionado con la adhesividad, actuando como barrera en los fenómenos de invasión y metástasis (5).

Entre las semejanzas de la glándula mamaria humana y canina están: La morfología del tumor pudiendo ser móvil o fijo, de aspecto sólido o quístico y de presentar rápido crecimiento e invasión en y a tejidos adyacentes como ocurre con los carcinomas; la presencia de receptores de estrógeno, progesterona y de factor de crecimiento epidermal 2(HER2) (6). Entre otras semejanzas están la metástasis a órganos como hígado, cerebro y hueso (7); la evolución clínica relacionada con la sobrevida de las pacientes y la heredabilidad en algunos casos $(8,9)$. Tales semejanzas motiva el estudio comparativo de la patología entre las dos especies, que implicará en mejores diagnósticos, tratamientos, pronósticos y prevención de las neoplasias malignas $(8,9)$.
El objetivo de la investigación fue comparar las características morfológicas de células normales y cancerosas de glándulas mamarias de mujeres y de perras, además; de intentar establecer una línea celular compuesta por células epiteliales usando técnicas de cultivo celular in vitro; como también comparar la expresión de una importante molécula de adhesión celular presente en los desmosomas (desmogleina1), por medio del ensayo inmuno- histoquímico en muestras incluidas en parafinas usando anticuerpos monoclonales.

\section{MATERIALES Y MÉTODOS}

La metodología de esta investigación realizada en seres humanos y animales fue aprobada por la comisión de ética de la Universidad Federal de Viçosa - Brasil según procesos 038/2008 y 033/2008 respectivamente.

Recolección de la muestra. Fueron colectados seis fragmentos del parénquima mamario normal de mujeres por mamoplastias realizadas en clínica de cirugía plástica, además; se colectaron tres muestras de tumores provenientes de mujeres y que fueron obtenidas por punción aspirativa con aguja gruesa (core biopsy), ambas en la ciudad de Viçosa-Minas Gerais-Brasil. Las muestras en perras de parénquima mamario normal y tumoral, fueron obtenidas por cirugías realizadas en el Hospital Veterinario de la Universidad Federal de Viçosa y fueron colectados 10 fragmentos normales y 14 fragmentos tumorales. 
Procesamiento de la muestra. Despues de la remoción quirúrgica, cada fragmento tanto normal como tumoral de mamas humana y canina, se transportaron en frascos con formaldehido tamponado al $10 \%$ en PBS, para ser procesados e incluidos en parafina. Se cortaron con grosor de $3 \mu \mathrm{m}$ y colorearon con Hematoxilina y Eosina (HE) (10). Seguidamente se analizaron las placas en microscopio de luz, agrupándose de acuerdo con los subtipos histológicos de los tumores mamarios humanos (OMS) y caninos (11), reconocidos por la Organización Mundial de la Salud y clasificadas como: $(n=12)$ adenocarcinomas tubulares complejos, $(n=2)$ carcinosarcoma provenientes de mama canina y $(n=3)$ adenocarcinomas tubulares invasivos, provenientes de la especie humana.

Las placas se sometieron a la técnica avidinabiotina-peroxidasa, utilizando anticuerpo monoclonal 32-2B (anti-desmogleína-1) $(12,13$ ). Las láminas con los cortes fueron desparafinadas con xilol y rehidratadas en alcohol $70 \%$ por 10 min. A continuación, fueron incubadas con $1 \%$ de $\mathrm{H}_{2} \mathrm{O}_{2}$ en metanol por 20 min y lavadas con agua destilada. Posteriormente se trataron con $0.1 \%$ de $\mathrm{CaCl}_{2}$ por $20 \mathrm{~min}$, se lavaron con TBS e incubaron por 30 min en un medio que contenía $1 \%$ de suero albumina bovino, medio de cultivo DMEM y $20 \%$ de suero fetal bovino. Después del procedimiento anterior, se aplicó anticuerpo primario anti-desmogleina-1 (32-2B) por una hora y las láminas se incubaron con anticuerpo anti-mouse IgG y biotinilado por una hora. Posteriormente, las láminas fueron lavadas con TBS e incubadas con el complejo avidina-biotinaperoxidasa $(A B C)$ por 15 min, y enseguida; se aplicó substrato diaminobenzidina (DAB) por 10 min. Las láminas fueron contracoloreadas con hematoxilina por tres minutos (13).

Cultivo celular. Para el cultivo celular, los fragmentos de las mamas normal y cancerosa de las dos especies, fueron transportados en frascos estériles que contenían $10 \mathrm{ml}$ de medio de cultivo DMEM (Dulbecco's Modified Eagles Médium) suplementado ( $8 \mathrm{ml}$ de medio de cultivo DMEM, $2 \mathrm{ml}$ de suero fetal bovino, $1 \mathrm{ml}$ de solución antibiótica penicilina/estreptomicina/ Fungizona, $20 \mu \mathrm{l}$ de hidrocortisona, $0.1 \mu \mathrm{l}$ de factor de crecimiento epidermal, $0.1 \mu \mathrm{l}$ de insulina, $0.1 \mu \mathrm{g}$ de toxina de cólera). Seguidamente con el auxilio de laminas de bisturí usadas en pares, dos en cada mano y posterior al corte de los fragmentos por medio de movimientos opuestos y en el mismo plano, fueron obtenidos fragmentos menores de aproximadamente $1 \mathrm{~mm} \times 1 \mathrm{~mm}$ y que se denominaron explantes. Estos explantes se introdujeron en frascos de cultivo con el auxilio de jeringas de $1 \mathrm{ml}$. Cerca de 20 explantes fueron colocados en dos filas equidistantes con separación de cerca de $0.5 \mathrm{~cm}$ uno del otro, en recipientes de poliestireno de $25 \mathrm{~cm}^{2}$. Sobre cada explante se adicionó una gota de medio de cultivo suplementado y enseguida los recipientes fueron acondicionados a $37^{\circ} \mathrm{C}, 5 \%$ de $\mathrm{CO}_{2}$ y $70 \%$ de humedad, de forma invertida (técnica conocida como gota invertida) por 24 horas. Pasado ese tiempo, los recipientes se colocaron en posición normal, siendo observados rutinariamente en microscopio de luz invertida (Leica DMIL). Está técnica está descrita en Freshney (12) y modificada en el laboratorio del Cáncer-UFV.

Para la obtención del cultivo puro de células epiteliales se utilizó la técnica de tripsinización blanda que consiste en adicionar $0.5 \mathrm{ml}$ de tripsina, diluida en $0.5 \mathrm{ml}$ de PBS (tripsina $0.125 \%$ ). Este tratamiento duró dos minutos, que tiene por objetivo remover los fibroblastos que quedan flojamente adheridos al sustrato, contrario a lo que sucede con las células epiteliales. La interrupción de ese proceso se dio con la adición de $5 \mathrm{ml}$ de medio de cultivo, suplementado con $1.25 \mathrm{ml}$ de suero fetal bovino.

\section{RESULTADOS}

Las características morfológicas de las mamas normales de la especie humana y de la especie canina fueron evidenciadas por la coloración con Hematoxilina y Eosina (Figura 1).

En carcinosarcomas provenientes de la especie canina $(n=4)$, existieron áreas de necrosis y ulceraciones que contaminaron el cultivo, haciéndolo inviable, razón por la cual; no se utilizaron en el estudio comparativo.

Cultivo de células provenientes de la glándula mamaria normal de perras. De las 20 muestras inmersas en cultivos, solo 14 se adhirieron al substrato, proporcionando la salida y la adhesión de las células en la superficie después de 10 días de cultivo (Figura 2A).

Aparentemente dos tipos de grupos celulares fueron observados. Un tipo en menor cantidad, compuesto por células pequeñas con morfología redondeada, dispuestas bien próximas unas de otras y con semejanza a las células epiteliales (Figura 2B). El otro tipo, mayor y más numeroso con morfología fibroblastoide y con células más separadas unas de otras, cuando comparas con las células epitelioides. A partir de esas observaciones y considerando la composición tisular de la estructura de la glándula mamaria, 


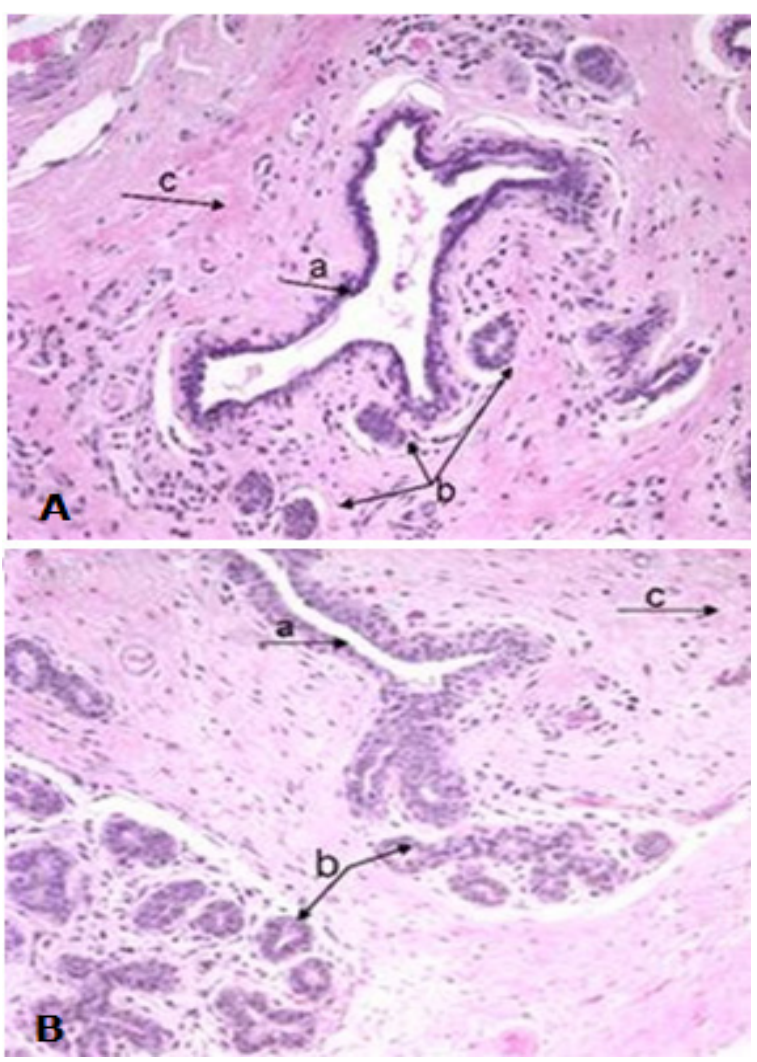

Figura 1. Fotomicrografías de estructuras constitutivas de la glándula mamaria. A.) Glándula mamaria normal de perra y B.) Glándula mamaria normal de mujeres, a) conducto, b) acinos, c) tejido conjuntivo denso (HE 400X). se puede presumir que el primer tipo celular está compuesto por células epiteliales y el segundo por células mesenquimales específicamente fibroblastos (Figura 2B).

Las células fibroblastoides presentan mayor tasa de proliferación cuando son comparadas con las células epitelioides, siendo necesaria su retirada porque ocupaban gran espacio en el frasco, limitando el espacio destinado para las células epitelioides (Figura 2C).

Después de 25 días de cultivo las células fibroblastoides fueron retiradas del cultivo. Con esta remoción las células epitelioides permanecieron adheridas al substrato del frasco de cultivo y se mantuvieron viables pero con crecimiento lento (Figura 2D). Después de 60 días de cultivo, las células epitelioides presentaron signos morfológicos de degeneración, como la contracción de la membrana celular, presencia de vacuolas citoplasmáticas (Figura 2E) y citoplasma con aspecto granuloso, terminando el proceso con la lisis celular.

Cultivo de células provenientes de tumores malignos (Adenocarcinoma tubular complexo) de la glándula mamaria de perras. De las 20 muestras inmersas en cultivos, solo seis se mantuvieron adheridos al substrato, proporcionando la migración y la adhesión de las células (Figura $3 \mathrm{~A}$ y $3 \mathrm{~B}$ ), ocurriendo a los cinco días de iniciado el cultivo.
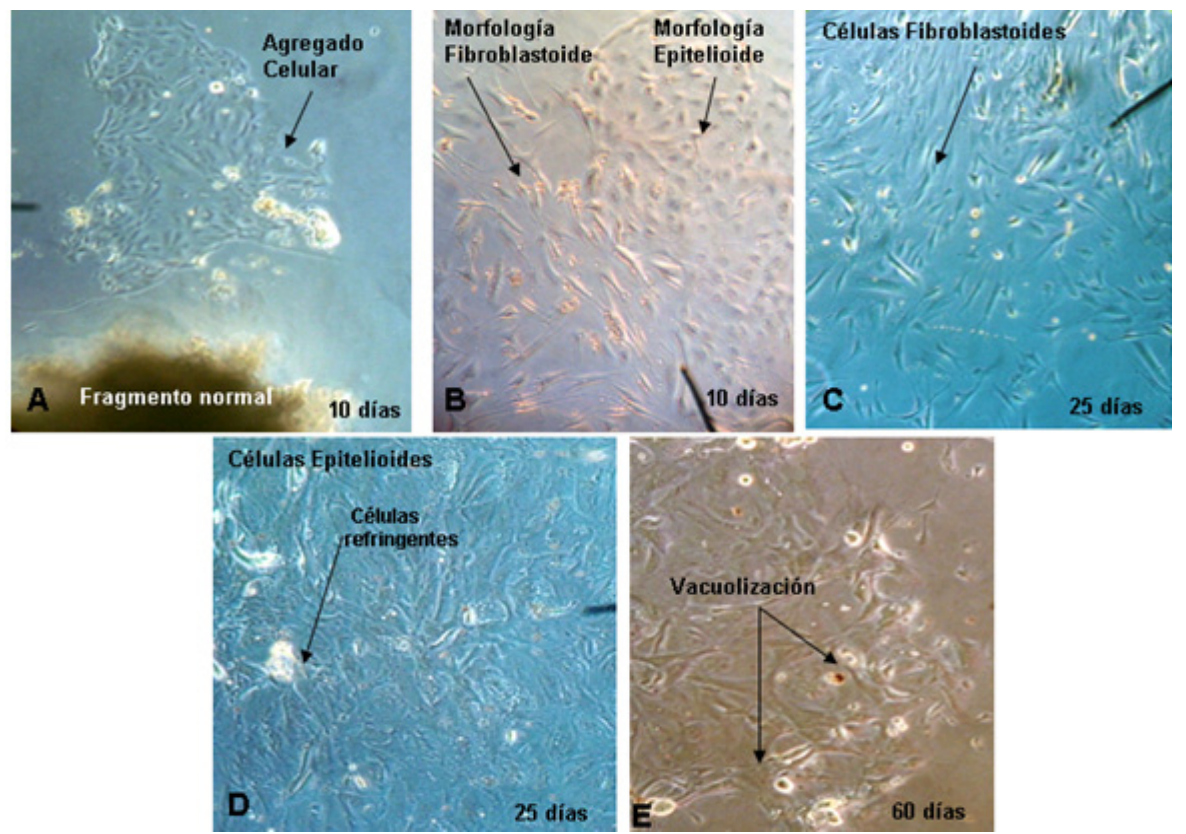

Figura 2. Fotomicrografías en microscopio de luz invertida de cultivo celular provenientes de la glándula mamaria normal de perras. (A) Células adheridas al substrato del frasco, formando agregado celular. Es posible observar el fragmento normal de donde se originaron las células, (B) Células con morfología fibroblastoide y células con morfología epiteliode, (C y D) proliferación celular. Se pueden observar células refringentes que indican división celular activa, (E) signos de degeneración que pueden evidenciarse por vacuolización citoplasmática (aumento de 200x). 

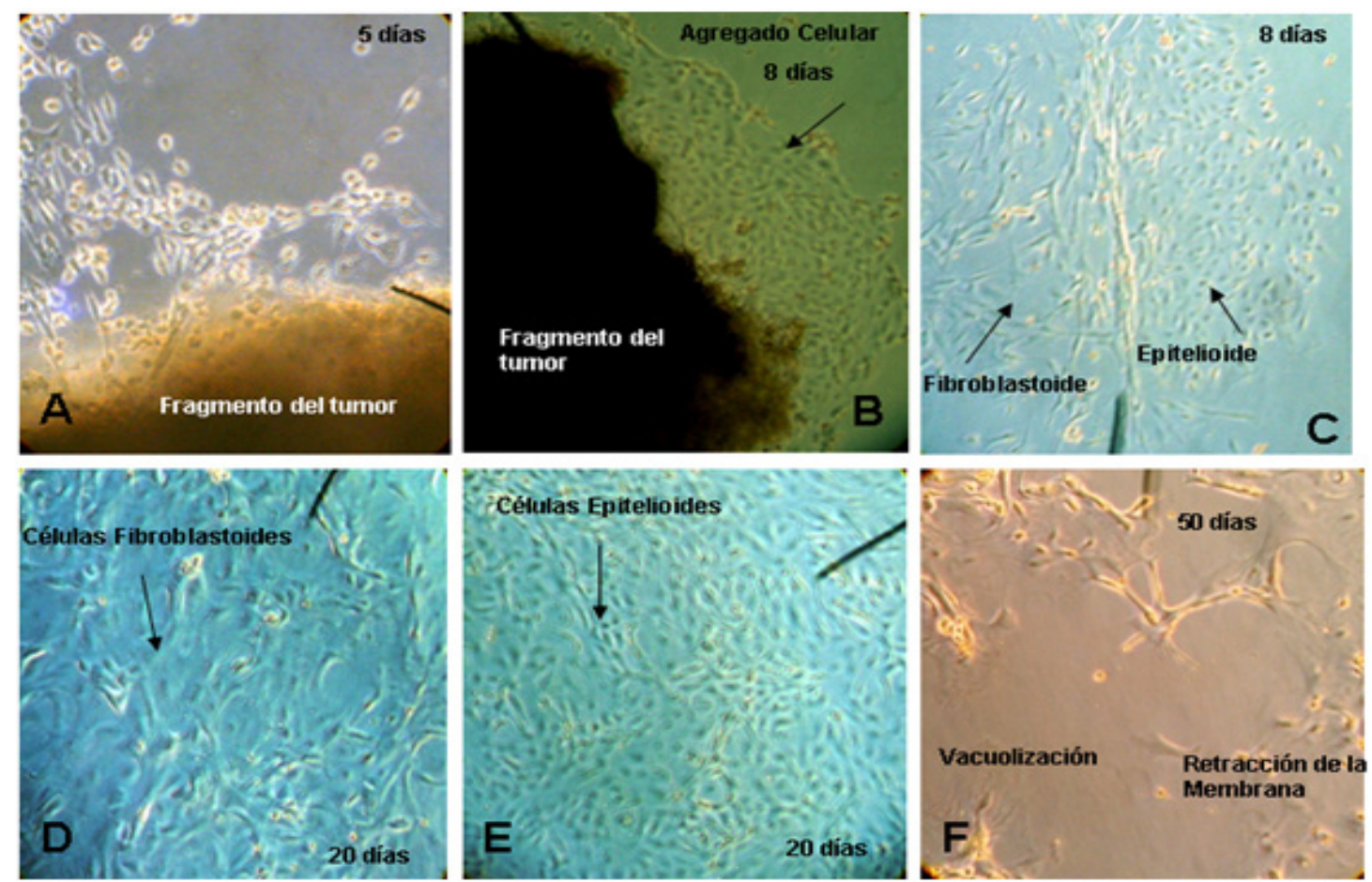

Figura 3. Fotomicrografías en microscopio de luz invertida de cultivo celular provenientes del tumor de glándula mamaria de perras (adenocarcinoma tubular infiltrante). (A) células migrando del fragmento, (B) células adheridas al substrato, formando gran agregado de característica epitelioide, (C) células con morfología fibroblastoide y células con morfología epitelioide, ( $D$ y E) intensa proliferación celular, ( $F$ ) signos de degeneración evidenciados por retracción de la membrana celular y vacuolización citoplasmática. Aumento de 200x.

Las células mantuvieron alta tasa de multiplicación con múltiples vacuolas citoplasmáticas, pleomorfismo celular y nucleolo central evidente. Fueron observados grupos de células próximas unas de otras con morfología epitelioide (Figura 3C). Además; se observaron otras células que se mantenían más separadas unas de otras con morfología alargada y características fibroblastoides, siendo clasificadas como fibroblastos (Figura 3C y 3D).

Cuando el cultivo alcanzó la semiconfluencia después de los 20 días, las células fibroblastoides fueron retiradas del cultivo. Las células epitelioides permanecieron en el frasco de cultivo manteniéndose viables por un tiempo, ya que después de 50 días comenzaron a presentar signos morfológicos de degeneración, entre los que se reportan la contracción de la membrana celular y vacuolas citoplasmáticas, finalizando el proceso con la lisis celular (Figura 3E y $3 F$ ).

\section{Cultivo de células provenientes de la glándula} mamaria normal de mujeres. En promedio, ocho de las 20 muestras inmersas en el frasco de cultivo se adhirieron a la superficie y proporcionaron la migración de las células, hecho que ocurrió a los 12 días de ser cultivadas (Figura 4-A y B).
Estuvieron presentes dos tipos de células: uno compuesto por células con morfología epitelioide y otro con morfología fibroblastoide. En razón a que el parénquima de la glándula mamaria está constituido por células epiteliales y el estroma por células mesenquimales, es probable que los tipos celulares fuesen epiteliales y mesenquimales, específicamente fibroblastos (Figura 4C y 4D).

Las células con la morfología epitelioide estuvieron viables y presentaron baja tasa de proliferación cuando son comparadas con las células con morfología fibroblastoide.

En 20 días de cultivo, las células fibroblastoides habían ocupado gran parte del frasco de cultivo. Se realizó una tripsinización blanda y posterior a ese procedimiento, las células epitelioides se mantuvieron adheridas a la superficie del frasco, siendo retiradas la mayor parte de las fibroblastoides. Las células epitelioides que permanecieron adheridas al substrato del frasco, se mantuvieron con baja proliferación y comenzaron a soltarse del substrato (Figura 4E). Con el propósito de separar las células y en la tentativa de estas de distribuirse mejor en el área del frasco, fue realizada una segunda 

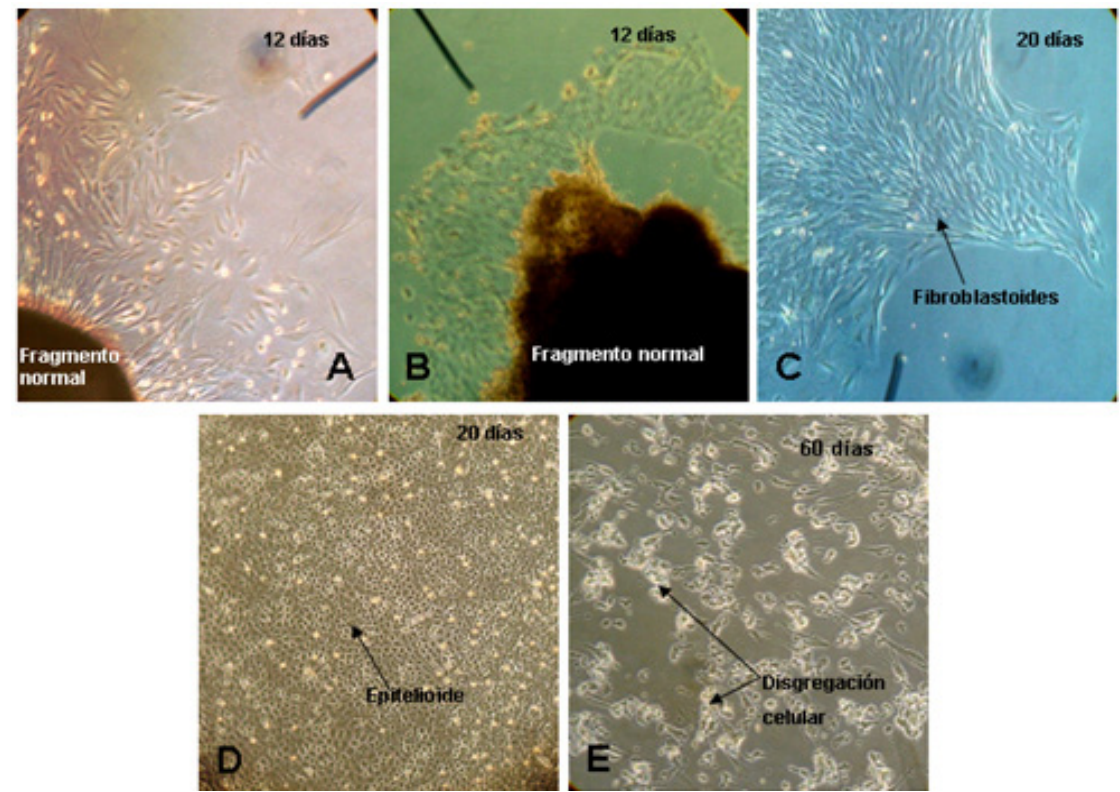

Figura 4. Fotomicrografía en microscopio de luz invertida de cultivo de células provenientes de la glándula mamaria normal de mujeres. ( $\mathrm{A}$ y $\mathrm{B}$ ) células adheridas al substrato del frasco, ( $\mathrm{C}$ y D) células con morfologías fibroblastoide y células con morfología epitelioide respectivamente, observándose proliferación celular de ambos tipos de células, (E) células desagregándose del substrato con destrucción y fragmentación de las mismas. Aumento de 200x.

tripsinización, no consiguiéndose adherencia de las mismas al substrato del frasco, por lo que se dio la lisis celular. Este cultivo se mantuvo por 60 días.
Cultivo de células provenientes de tumores malignos (Adenocarcinoma tubular invasivo) de glándula mamaria de mujeres. 10 de las 20 muestras inmersas en el frasco de cultivo se mantuvieron adheridos al substrato, proporcionando así la migración de las células, hecho que ocurrió después de siete días (Figura 5A).
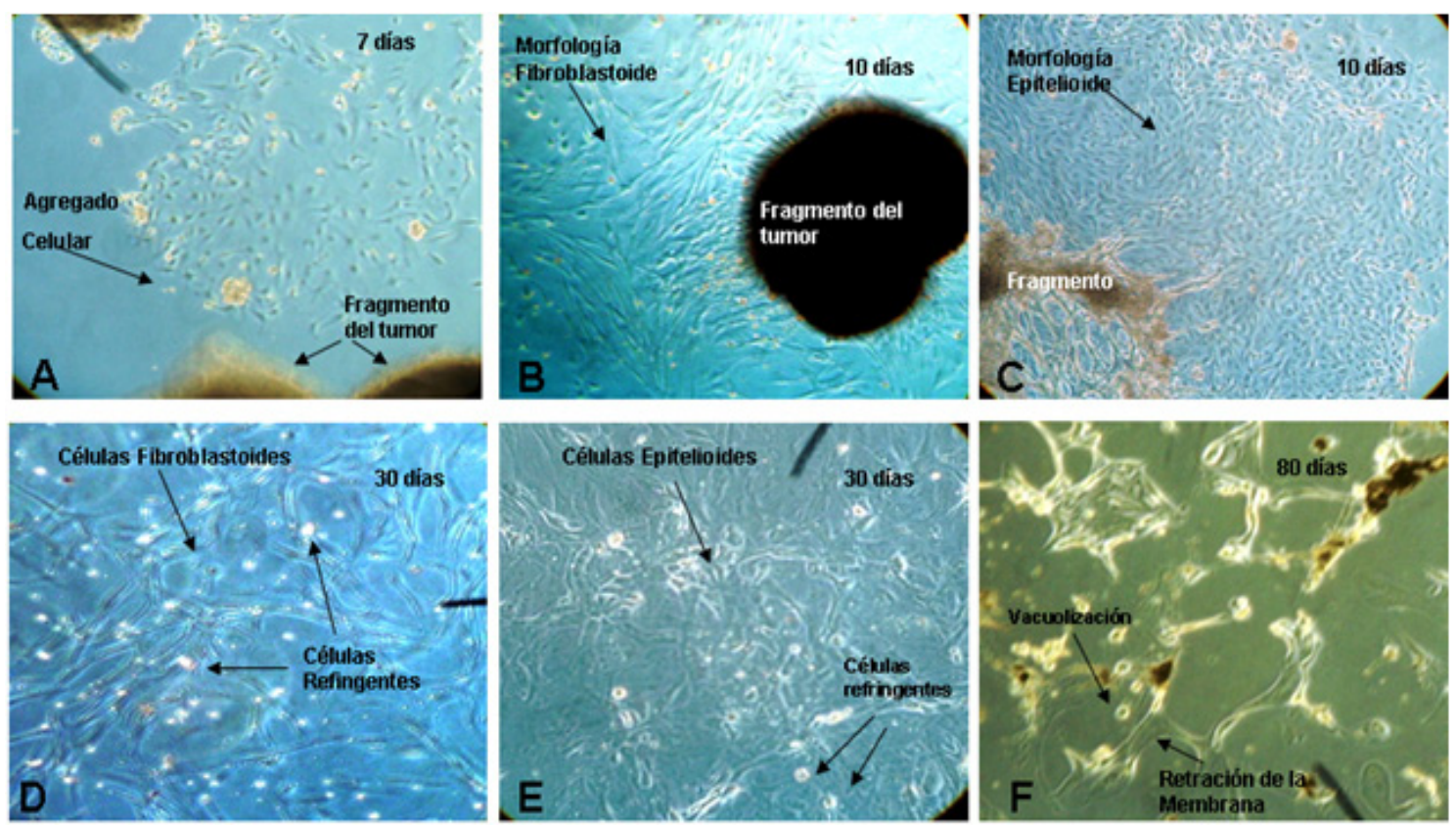

Figura 5. Fotomicrografía en microscopio de luz invertida de cultivo de células provenientes de tumores malignos (adenocarcinoma tubular invasivo) de glándula mamaria de mujeres. (A) Grupo de células adheridas al substrato del frasco, (B y C) Células con morfología fibroblastoide y epitelioide respectivamente, ( $D$ y E) Proliferación celular mostrando células refringentes indicativo de división celular activa, (F) Signos de degeneración celular evidenciados por la retracción de la membrana y vacuolización. Aumento de 200x. 
Las células mantuvieron alta tasa de multiplicación, observándose a los 10 días grupos celulares próximos a los fragmentos (Figura 5B y 5C). Se observaron grupos celulares bien próximos unos de otros, con morfología epitelioide (Figura 5C). También se observaron otras células que se mantenían más separadas unas de otras con morfología alargada fibroblastoide (Figura 5B).

Después de 30 días de cultivo, debido a la alta proliferación celular fibroblastoide y consecuente con el gran número, fue realizada la tripsinización blanda. Las células epitelioides permanecieron adheridas al substrato del frasco del cultivo inicial (Figura 5D y 5E).
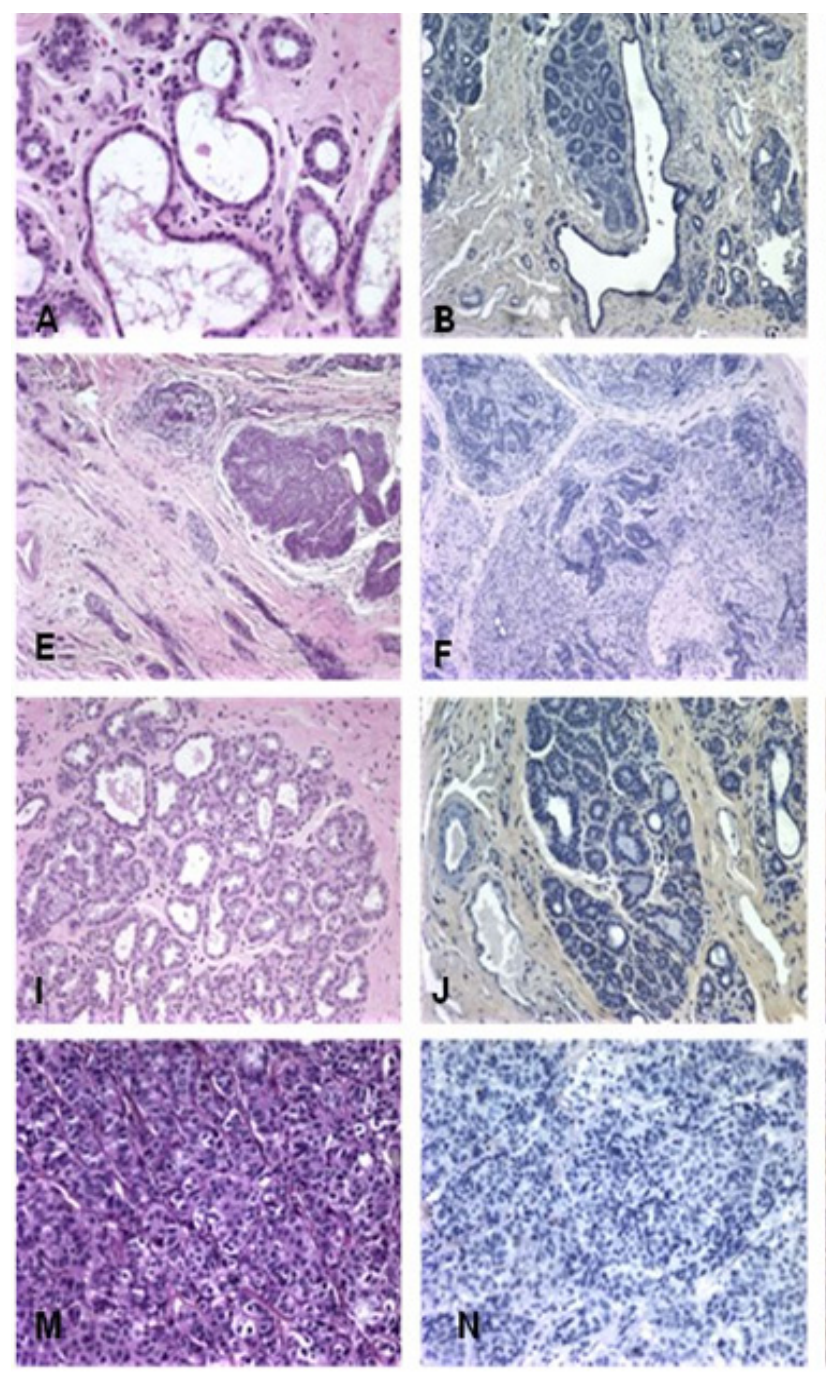

Las células epitelioides permanecieron viables en el cultivo pero con una tasa de proliferación baja. Ese cultivo se mantuvo durante 80 días, tiempo en el cual; las células epitelioides comenzaron a presentar signos morfológicos de degeneración, con retracción de la membrana celular y muchas vacuolas citoplasmáticas culminando el proceso con la lisis celular (Figura 5F).

Evaluación inmuno-histológica. Los ensayos inmuno-histoquímicos en tejidos de glándula mamaria normal de la especie canina demostraron la presencia de los desmosomas (localizados en los límites intercelulares) por medio de la inmuno-marcación con el anticuerpo anti-desmogleina-1. Los desmosomas aparecen marcados con intensa coloración café oscura
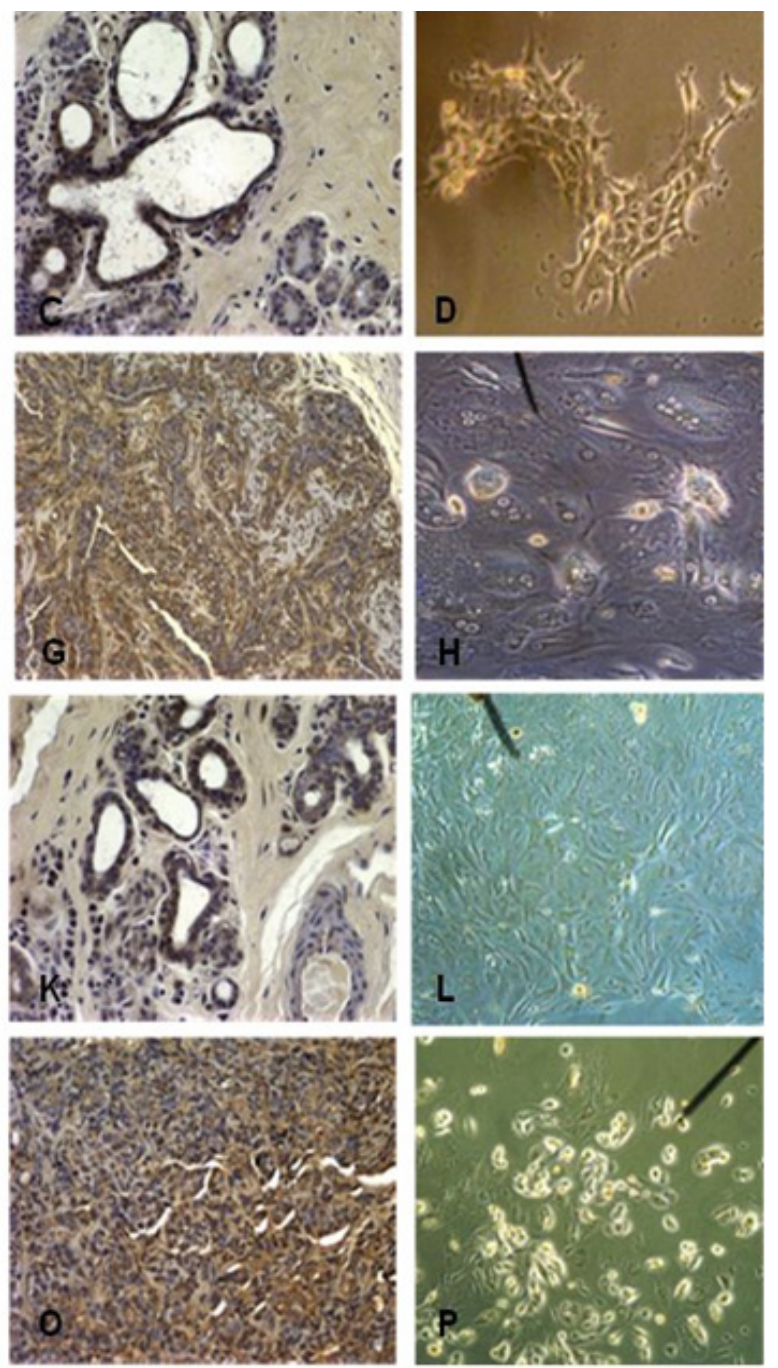

Figura 6. Fotomicrografía de la glándula mamaria normal y tumoral (adenocarcinoma tubular) provenientes de las especies humana y canina. Coloración con $\mathrm{HE}(\mathrm{A}, \mathrm{E}, \mathrm{I}$ y $\mathrm{M})$, reacción inmuno-histoquímica utilizando anticuerpo monoclonal 32-2B (anti-desmogleina-1): Control negativo - $C N(B, F, J$ y $N$ ) y marcación con el anti-cuerpo 32-2B ( $C, G, K$ y O). Cultivo de células ( $D, H, L$ y P), ( G y O) muestran coloración difusa y clara. (C y K) muestran intensa coloración en las estructuras de la glándula mamaria de ambas especies. Aumento de 200x en los microscopios de luz y de luz invertida. 
y se localizaron en la superficie lateral de las células (periferia celular), formando los túbulos y alveolos (Figura 6C) que constituyen el parénquima de la mama. Esta coloración se encuentra tan homogénea que dificulta la visualización de los límites celulares, dando la falsa impresión que los desmosomas se localizaban en todas las regiones celulares, cuando en verdad se encontraban en la región de contacto entre las células.

De modo semejante los tejidos de la especie humana presentaron las mismas características antes mencionadas (Figura 6K). La coloración café oscura se encontraba tan intensa que dificultó la visualización de los límites celulares. Al contrario de las células normales, las células cancerosas (Adenocarcinoma tubular complexa) de la glándula mamaria canina presentaron cambios en el patrón de coloración, que se torno más clara y difusa en los citoplasmas de las células correspondientes al parénquima de la glándula mamaria (Figura 6G). Lo mismo aconteció con las células cancerosas (Adernocarcinoma tubular invasivo) de la glándula mamaria humana, que presentaron los mismos cambios en el patrón de coloración y que pasó a ser difusa y citoplasmática (Figura 60).

\section{DISCUSIÓN}

Líneas de células cancerosas de la glándula mamaria han sido utilizadas como modelo para estudio del cáncer de la glándula mamaria $(14,15)$. Por lo anterior, uno de los objetivos de esta investigación fue la de intentar establecer líneas de células epiteliales provenientes de la glándula mamaria de las especies humana y canina, sirviendo de instrumento para futuros estudios. Desde el establecimiento de la primera línea de células de carcinoma de mama por Lasfagues y Ozzello (16), pocas fueron las líneas establecidas con suceso (17).

Durante la realización de esta investigación fue posible cultivar células normales y cancerosas (Adenocarcinoma tubular) de ambas especies. Los grupos de células epiteliales que se adhirieron a los frascos tenían dependencia de las estromales, pues en la medida en que las células fibroblastoides eran retiradas, las células epitelioides detenian su crecimiento. Según Bhowmick et al (18), la interacción de las células del estroma es importante para la progresión y para el desarrollo de las células epiteliales. Esta interacción es mediada por señales de componentes de la matriz extracelular que inducen la proliferación de las células epiteliales.
A pesar de la dependencia de las epiteliales con las mesenquimales, la alta tasa de proliferación de las fibroblastoides impidió el desarrollo de las epitelioides, perjudicando su expansión.

Considerando que uno de los objetivos de este trabajo fue el de establecer una línea de células epiteliales, se hizo necesario retirara del cultivo las células con morfología fibroblastoide. De acuerdo con Lasfargues y Ozzello (16), los componentes del estroma tisular de la glándula se oponen a la migración de las células epiteliales en cultivo, formando barreras que impiden su libre desarrollo.

Se observó baja actividad de proliferación de las células normales de las especies humana y canina, cuando son comparadas con las cancerosas de las dos especies. De acuerdo con McDonald (19), la baja actividad proliferativa de las células derivadas del parénquima de la mama normal está relacionada con las diversas propiedades de las normales, como la dependencia de anclaje, la inhibición de crecimiento densidad-dependiente, la gran dependencia de suero, de factor de crecimiento y extensión de vida finita. Siendo así, el cultivo de las células normales se torna aun mas difícil que el cultivo de las cancerosas, porque estas poseen intensa actividad celular, mutaciones genéticas 0 epigenéticas en los genes 0 proteínas relacionadas con la proliferación y la diferenciación celular (15).

Los estudios relacionados con el cultivo primario de tejidos provenientes de glándula mamaria, constituyen un paso inicial y de mucha importancia para el establecimiento de líneas celulares estables. Los resultados alcanzados permiten afirmar que es necesario utilizar frascos de cultivos con substrato adecuados y semejantes a la matriz extracelular para obtener éxito en el establecimiento de las líneas de células epiteliales de glándula mamaria, tanto de mujeres como de perras, una vez que los frascos utilizados en este estudio fueron de cultivo, con superficies no cubiertas por sustancias como colágeno y laminina que constituyen esa matriz. Además, el uso de hormonas y factores de crecimiento adicionales deben ser probadas, proporcionando a las células en cultivo el ambiente más semejante in vivo.

En la evaluación inmuno-histoquímica se observó presencia de los desmosomas por medio de la interacción del anticuerpo 32-2B con la desmogleina-1, identificada por la intensa coloración de la membrana de las células epiteliales 
correspondientes a los ductos y acinos de la glándula mamaria normal de las especies humana y canina. La intensidad de la coloración sugiere la semejanza en los niveles de la expresión de la desmogleina-1, en los desmosomas de las dos especies.

Como la embriología, la anatomía y la histología de la glándula mamaria de la especie canina (perras) son parecidas a la de la especie humana (mujeres) la semejanza en el patrón de coloración para el análisis de los desmosomas de esas especies se justifica. Además, se está de acuerdo con Vilela et al (14), quienes desarrollaron el anticuerpo 32-2B y probaron en tejidos normales de glándula mamaria humana, consiguiendo la observación de los desmosomas en los límites de la células que constituyen los ductos y acinos de la glándula mamaria y en otros tejidos como el glándula salivar submandibular, del uréter y del estómago.

Comparando los resultados obtenidos por medio de la coloración de las células normales de las especies humana y canina, fue posible analizar la reducción en la coloración de células cancerosas de ambas especies. Estos resultados demostraron que las estructuras relacionadas con la adhesión celular (en este caso desmosomas) pueden estar alteradas. De acuerdo con Dusek et al (20), Chidgey y Dawson (5) en condiciones patológicas como el cáncer, la estabilidad desmosómica puede estar alterada. Para Yaldizl et al (21) las células que dan origen a los tumores epiteliales como los carcinomas presentan baja adhesividad con otras células y con la matriz extracelular. De acuerdo con González et al (22), los principales mecanismosenvueltos en el proceso son: modificaciones e irregularidades en la membrana plasmática y reducción de moléculas de adhesión, entre las quesedestacan las caderinasy la disminución de los iones calcio en las células, proporcionando la internalización de los desmosomas.

Las células cancerosas de ambas especies presentan también una coloración difusa y citoplasmática. Según Dusek et al (20), la coloración citoplasmática puede darse en respuesta a las condiciones de baja concentración de calcio, que desestabilizan los desmosomas dando como resultado su internalización.
Para Roa et al (23), los tumores agresivos localizados y las lesiones metastásicas presentan disminución o ausencia en la expresión de las caderinas. Esta pérdida de expresión puede estar asociada fuertemente con la hipermetilación de los sitios, en el inicio de la transcripción de este gen, así como mutaciones epigenéticas observadas en algunos carcinomas de glándula mamaria (24). La disminución de la interacción de las caderinas con otras estructuras de adhesión celular permite a las células cancerosas su fácil dislocación y su infiltración en los tejidos vecinos (25).

En algunos tumores malignos se ha demostrado que la expresión de estas moléculas de adhesión está relacionada con el pronóstico y su capacidad de generar metástasis. La baja expresión de las caderinas en carcinomas de glándula mamaria ha sido indicativa de baja sobrevida de pacientes $(22,24,25)$.

En conclusión, con base en los resultados histológico, inmuno-histoquímico y de cultivo celular de tejidos normales y tumorales (Adenocarcinoma tubular) de glándula mamaria de las especies humana y canina se puede concluir que las células de la glándula mamaria normal de perras tienen semejanzas con las células de la glándula mamaria normal de mujeres en los aspectos histológicos in vitro y en la expresión de la proteína desmosómica desmogleina-1. In vitro, hay baja actividad de proliferación de las células mamarias normales humana y canina, cuando son comparadas con las cancerosas mamarias de ambas especies. Los grupos de células epiteliales que se adhirieron a los frascos, tienen dependencia de las estromales, ya que en la medida que las células fibroblastoides fueron retiradas, las células epitelioides paran su crecimiento. Comparando los resultados obtenidos por medio del análisis inmuno-histoquímico de las células normales de las especies humana y canina, fue posible analizar la reducción de la coloración en células cancerosas de ambas especies, demostrando que las estructuras relacionadas con la adhesión celular (en este caso desmosomas) pueden estar alteradas.

\section{REFERENCIAS}

1. Junqueira LC, Carneiro J. Glândula mamária. In: Histologia Básica. Rio de Janeiro: Guanabara Koogan, 2004.

2. Kumar V, Abbas AK, Fausto N. Mama feminina. In: Robbins S., Cotran R. (7th Ed). Bases Patológicas das Doenças. Rio de Janeiro: Mosby Elsevier 2005.
3. Garrod D, Chidgey M. Desmosome structure, composition and function. Biochim Biophys Acta 2007; 1778:572-587.

4. Vilela MJ, Hashimoto T, Nishikawa T, North $A J$, Garrod DA. A simple epithelial cell line (MDCK) shows heterogeneity of desmoglein isoforms, one resembling pemphigus vulgaris antigen. ] Cell Sci 1995; 108:1743-1750. 
5. Chidgey M, Dawson C. Desmosomes: a role in cancer? Br J Cancer 2007; 96:1783-1787.

6. Gama A, Alves A, Schmitt F. Identification of molecular phenotypes in canine mammary carcinomas with clinical implications: application of the human classification. Virchows Arch 2008; 453:123-132.

7. Geraldes M, Gartner F, Schmitt FN. Immunohistochemical study of hormonal receptors and cell proliferation in normal canine mammary glands and spontaneous mammary tumours. Vet Rec 2000; 146:1140-1148.

8. Peleteiro MC. Tumores mamários na cadela e na gata. Rev Port Ciênc Vet 1994; 89:10-29.

9. Bremnes RM, Vere R, Hirsch FR, Franklin WA. The e-cadherin cell-cell adhesion complex and lung cancer invasion, metastasis and prognosis. Lung Cancer 2002; 36:115-124.

10. Tolosa EMC, Rodrigues C], Behmer AO, Freitas Neto AG. Manual de técnicas para histologia normal e patológica. São Paulo: Manole, 2003.

11. Misdorp, W, Else RW, Hellmen E, Limpiscomb T.P. Histological classification of the mammary tumors of the dog and the cat. In: WORLD HEALTH ORGANIZATION. International Histological Classification of Tumors of Domestic Animals. Geneva: World Health Organization 1999; 2: 415-422.

12. Freshney RI. Culture of Animal Cells: manual of basic techniques. 4th ed. New York: Wiley-Liss, 2000.

13. Hsu SM, Raine L, Fanger $H$. The use of antiavidin antibody and avidin-biotin-peroxidase complexe in immunoperoxidase technics. Am J Clin Pathol 1981; 76:816-821.

14. Vilela MJ, Parrish EP, Wright DH, Garrod DR. Monoclonal antibody to desmosomal glycoprotein-1. A new epithelial marker for diagnostic pathology. J Pathol 1987; 153:365-375.

15. Vargo-Gogola T, Rosen JM. Modelling breast cancer: one size does not fit all. Nat Rev Cancer 2007; 7:659-672.
16. Lasfargues EY, Ozzello L. Cultivation of human breast carcinomas. J Natl Cancer Inst 1958; 21:1131-1147.

17. Peixoto EBMI. Estabelecimento e caracterização de linhagens celulares de tumores primário da mama. Monografia (Biologia Animal). Brasil: Universidade Federal de Viçosa; 2001.

18. Bhowmick NA, Neilson EG. Moses HL. Stromal fibroblasts in cancer initiation and progression. Nature 2004; 432:332-337.

19. Mcdonald C. Primary culture and establishment of cell line. In: Davis JM. (Ed.). Basic Cell Culture: A Practical Approach. New York: Oxford University, 1996; 149-180.

20. Dusek RL, Godsel LM, Green KJ. Discriminating roles of desmosomal cadherins: beyond desmosomal adhesion. J Dermatol Sci 2007; 45:7-21.

21. Yaldizl M, Hakverdi AU, Bayhan G, Akkus Z. Expression of e-cadherin in squamous cell carcinomas of the cervix with correlations to clinicopathological features. Eur ] Gynaecol Oncol 2005; 26:95-98.

22. González JSL, López MIV, Torres AP, Garcia AH. Expressión de la molécula e-caderin e líneas celulares de carcinomas de pulmón. Rev Inst Nal Enf Resp 1997; 10:7-12.

23. Roa Esterio I, Villaseca MA, Araya Oróstica JC, Roa JC, Aretxabala Urquizar X, Miranda M. Moléculas de adhesión celular y cáncer. Rev Chil Cir 2001; 53:504-510.

24. Takeichi M. Cadherins in cancer: implications for invasion and metastasis. Curr Opin Cell Biol 1993; 5:806-811.

25. Teixeira MJD,Sobral APV, Abreu-e-Lima MC, Maia FCL, Christilis M, Souza DMB.Adrião $M$, Wischeal A. Avaliação da superexpressão da proteína p53 e das mutações no éxon 8 do gene TP53 em carcinoma mamários caninos e glândulas normais.Pesq. Vet. Bras. 31(6):521526, 2011. 